\title{
EDUKASI FINTECH DAN KEWIRAUSAHAAN BAGI PELAKU UMKM KECAMATAN PARUNG, KABUPATEN BOGOR
}

\author{
Suharyati $^{1}$, Ediwarman ${ }^{2}$ \\ ${ }^{1}$ Fakultas Ekonomi, Universitas Pembangunan Nasional Veteran Jakarta \\ Email:yatididi01@gmail.com \\ ${ }^{2}$ Fakultas Ekonomi, Universitas Pembangunan Nasional Veteran Jakarta \\ Email: ediwarman.upn@gmail.com
}

\begin{abstract}
ABSTRAK
Di era globalisasi dan digitalisasi seperti sekarang ini, persaingan bisnis semakin meningkat, baik dalam skala kecil maupun besar. Teknologi semakin canggih dan sudah selayaknya pelaku usaha menyesuaikan dengan kebutuhan berbagai layanan yang telah menggunakan teknologi sesuai keinginan dan kebutuhan konsumen. Saat ini banyak bermunculan layanan keuangan berteknologi yang dikenal dengan fintech sejalan dengan gaya hidup konsumen masa kini yang ingin serba praktis, mudah dan aman serta produk yang berkualitas. Untuk itu pelaku UMKM dituntut untuk lebih meningkatkan kemampuan serta keterampilannya dalam menjalankan usahanya. Metode pengabdian kepada masyarakat yang dilakukan di desa Iwul kecamatan Parung ini berupa edukasi mengenai fintech dan kewirausahaan serta pembekalan mengenai cara mengunduh aplikasi fintech. Peserta pengabdian kepada masyarakat ini berjumlah 34 orang pelaku UMKM, dengan capaian hasil mengenai pemahaman fintech maupun kewirausahaan masih dibawah 70\%. Sehingga kegiatan seperti ini masih perlu dilakukan secara intensif lagi agar terjadi peningkatan kemampuan dan keterampilan pelaku UMKM baik dalama hal layanan keuangan yang berteknologi maupun kewirausahaan. Hal ini perlu dukungan berbagai pihak khususnya pemda setempat dan dinas UMKM.
\end{abstract}

Kata kunci: Fintech, Entrepreneurship, Interpersonal skill, UMKM

\section{PENDAHULUAN}

Era globalisasi dan digitalisasi, membuka peluang sekaligus tantangan bagi dunia usaha seiring dengan meningkatnya kemajuan teknologi di berbagai bidang. Menurut Asosiasi Penyelenggara Jasa Internet Indonesia (APJII), sekitar 143 juta orang telah terhubung jaringan internet pada tahun 2017 dari 262 juta penduduk Indonesia. Mayoritas pengguna internet sebanyak 72,41 persen masih dari kalangan masyarakat urban yang pemanfaatannya bukan hanya untuk berkomunikasi tetapi juga membeli barang, memesan transportasi, hingga berbisnis dan berkarya. Pengguna internet di Tanah Air sebanyak 49,52 persen berada pada usia muda, berkisar 19 hingga 34 tahun (Kompas.com,2018).

Sektor finansial memiliki peran yang penting untuk mendukung kekuatan perekonomian suatu Negara. Dengan perkembangan teknologi yang semakin maju, sektor finansial juga turut mengalami perkembangan ke arah yang lebih modern dan praktis. Bisnis teknologi finansial atau dalam bahasa Inggris disebut financial technology (fintech) kini sedang naik daun di Indonesia. www.jurnal.id-agustus-2016.

Satria (2018) mengemukakan pada era digital, dimana teknologi menjadi kunci penting dalam memenangkan persaingan dalam bisnis. Penyedia jasa keuangan yang masih menggunakan cara yang konvensional harus beralih kearah yang lebih inovatif dalam memberikan pelayanan yang memuaskan pada konsumen. era digital dan inovasi memaksa pelaku-pelaku bisnis untuk terus berevolusi dengan inovasi-inovasi yang dekat dengan kebutuhan konsumen. pelayanan yang diberikan oleh fintech dapat dengan sangat mudah di akses oleh konsumen. http://feb.ub.ac.id 
Bagi masyarakat yang kehidupannya jauh dari perkotaan dan belum mengenal lebih dalam tentang perbankan, Financial Technology (Fintech) merupakan suatu terobosan dalam teknologi yang menjadi penghubung antara sektor finansial dengan pengguna atau masyarakat umum. Fintech sangat berpotensi menjadi salah satu solusi untuk mengatasi masalah yang sedang ada di masyarakat. Fintech dapat diartikan sebagai pemanfaatan perkembangan teknologi informasi untuk meningkatkan layanan di industri keuangan. Kebutuhan masyarakat, mendorong para pelaku jasa keuangan untuk terus melakukan inovasi dan transformasi dari transaksi secara tradisional ke dalam bentuk digital, dengan proses yang lebih singkat, mudah, dan terjangkau dengan adanya platform digital. (https://konsumen.ojk.go.id/)

Otoritas Jasa Keuangan (OJK) mengeluarkan Peraturan OJK Nomor 13/POJK.02/2018 tentang Inovasi Keuangan Digital di Sektor Jasa Keuangan sebagai ketentuan yang memayungi pengawasan dan pengaturan industri Financial Technology (Fintech). Peraturan ini dikeluarkan OJK mengingat cepatnya kemajuan teknologi di industri keuangan digital yang tidak dapat diabaikan dan perlu dikelola agar dapat memberikan manfaat sebesarbesarnya untuk kepentingan masyarakat. Inovasi keuangan digital perlu diarahkan agar menghasilkan inovasi keuangan digital yang bertanggung jawab, aman, mengedepankan perlindungan konsumen dan memiliki risiko yang terkelola dengan baik. Peraturan ini juga dikeluarkan sebagai upaya mendukung pelayanan jasa keuangan yang inovatif, cepat, murah, mudah, dan luas serta untuk meningkatkan inklusi keuangan, investasi, pembiayaan serta layanan jasa keuangan lainnya (detik.com,2018)

Peraturan Presiden (Perpres) No. 166/2014 tentang Program Percepatan Penanggulangan Kemiskinan telah dilakukan dengan berbagai cara dan strategi penanggulangan kemiskinan yang berorentasi material, sehingga keberlanjutannya sangat tergantung pada ketersediaan anggaran, komitmen pemerintah dan inisiatif masyarakat untuk menanggulangi kemiskinan dengan cara mereka sendiri. Ragam program penanggulangan kemiskinan selama ini yang berorientasi material, belum banyak berdampak pada pengurangan penduduk miskin. (Fajar, 2009), model alternatif pengentasan kemiskinan seyogianya berorientasi nonmaterial dan diawali dengan pembentukan agen pembaharu yang bermental wirausaha sehingga mampu menjadi penggerak pembedayaan masyarakat. Lestari (2006) model pelatihan yang berorientasi pada pengembangan jiwa kewirausahaan mampu meningkatkan daya saing masyarakat kalangan bawah. Sehubungan itu, mengembangkan suatu model pelatihan kewirausahaan berlatar pada kondisi ekologis dan budaya lokal.

Melihat kondisi tersebut, diperlukan penguatan organisasi dan peningkatan partisipasi anggota masyarakat dalam kegiatan-kegiatan yang sifatnya produktif. Globalisasi ekonomi membuka kesempatan pasar yang luas bagi suatu perusahaan maupun pelaku UMKM. Hal ini tentu menimbulkan persaingan bagi para pelaku pasar agar dapat mencapai kinerja yang lebih baik. Saat ini perusahaan harus bersaing dalam penggunaan teknologi dan inovatif guna meraih pangsa pasar yang lebih luas. Pengenalan akan teknologi baru dibidang keuangan ini harus disosialisasikan kepada masyarakat dan sudah merupakan tanggungjawab kita bersama, khususnya perguruan tinggi. Berdasarkan hal tersebut, maka Fakultas Ekonomi dan Bisnis UPN Veteran Jakarta, berupaya untuk membantu masyarakat kecamatan Parung untuk melakukan edukasi mengenai Financial Technology dan kewirausaahaan bagi pelaku UMKM dengan tujuan memberikan pemahaman dan pelatihan penggunaan aplikasi keuangan dengan 
mempergunakan smartphone dan upaya peningkatan keunggulan bersaing melalui kewirausahaan.

Pemahaman akan penggunaan Fintech dan kewirausahaan ini mempunyai kontribusi dalam percepatan laju ekonomi daerah yang berdampak pada peningkatan ekonomi Indonesia pada umumnya. Kecamatan Parung, kabupaten Bogor yaitu memiliki sembilan desa dimana kondisi desa berada jauh dari pusat keramaian sehingga untuk melakukan transaksi dengan lembaga perbankan dan lembaga keuangan formal mengalami kendala. Dengan kemajuan teknologi dibidang keuangan, berada jauh dari perkotaan seharusnya bukan merupakan hambatan lagi untuk melakukan transaksi keuangan. Terobosan dari Fintech mampu mengatasi permasalahan transaksi keuangan pelaku UMKM dengan lebih mudah dan cepat.

Lokasi atau tempat dilaksanakannya pengabdian kepada masyarakat ini adalah di Kecamatan Parung, Desa Iwul. Desa Iwul dikenal sebagai desa wisata, dikarenakan banyaknya kegiatan usaha UMKM dengan berbagai macam produk, yaitu kuliner, fashion, kerajinan tangan,dan berbagai kegiatan jasa.

\section{Permasalahan}

Berdasarkan latar belakang yang meliputi kondisi obyektif, profil wilayah dan serta peluang yang ada bagi UMKM Kecamatan Parung, Kabupaten Bogor maka dibuat perumusan masalah yaitu pentingnya Edukasi Fintech dan Kewirausahaan bagi pelaku UMKM khususnya sektor mikro melalui edukasi dan pembekalan teknologi keuangan sebagai sarana layanan keuangan bahkan permodalan bagi UMKM adalah sangat penting dilakukan.

\section{METODE PELAKSANAAN}

\section{Solusi yang ditawarkan}

Dalam penyelesaian masalah mengenai upaya pemberdayaan masyarakat ini, dilakukan dengan memberikan edukasi fintech dan kewirausahaan kepada para UMKM Kecamatan Parung, Kabupaten Bogor, khususnya desa Iwul sehingga pelaku UMKM dapat meningkat pemahaman tentang pemanfaatan teknologi layanan keuangan masa kini, ketrampilan serta kemampuan sebagai wirausaha dalam peningkatan keunggulan bersaing.

\section{Metode Pendekatan}

Edukasi dan pembekalan dilakukan dengan cara :

1. Memberikan edukasi mengenai fintech dan kewirausahaan dengan metode ceramah / paparan dan menggunakan LCD.

2. Pembekalan materi teknologi layanan keuangan berupa cara mengunggah aplikasi keuangan. 
Tabel 1. Prosedur kerja

\begin{tabular}{cll}
\hline $\begin{array}{c}\text { TAHAP } \\
\text { KE }\end{array}$ & \multicolumn{1}{c}{ KEGIATAN } & \multicolumn{1}{c}{ INDIKATOR } \\
\hline & $\begin{array}{l}\text { a. } \text { Edukasi fintech dan kewirausahaan } \\
\text { b. Dalam kegiatan ini peserta } \\
\text { mendengarkan ceramah dan } \\
\text { melakukan diskusi/tanya jawab }\end{array}$ & $\begin{array}{l}\text { Dilakukan test untuk menilai pencapaian } \\
\text { pemahaman materi }>70 \%\end{array}$ \\
\hline & $\begin{array}{l}\text { Dalam Pembekalan ini peserta langsung } \\
\text { ikut untuk mempraktekkan cara unduh } \\
\text { aplikasi }\end{array}$ & $\begin{array}{l}\text { Dapat mengunggah produk melalui sarana } \\
\text { internet }>60 \%\end{array}$ \\
\hline
\end{tabular}

\section{Pelaksanaan Kegiatan}

Kegiatan pengabdian masyarakat fintech dan kewirausahaan ini yang ditujukan bagi para UMKM di Desa Iwul, Kecamatan Parung, Kabupaten Bogor, dilakukan dengan tahapan yaitu tahap awal melakukan perijinan untuk melaksanakan program Pengabdian kepada masyarakat kepada mitra dengan melakukan studi lapangan untuk mempelajari masalah yang menjadi permasalahan prioritas mitra dan mempelajari pengaruh budaya setempat terhadap permasalahan masyarakat yang ada setelah itu melakukan kerjasama dengan Forum UMKM Kecamatan Parung untuk melaksanakan program pengabdian kepada masyarakat sebagai solusi terhadap permasalahan prioritas mitra.

Dalam tahap pelaksanaan melakukan pengabdian kepada masyarakat pada mitra, dengan cara melakukan pembelajaran tentang teknologi layanan keuangan (Fintech) dan kewirausahaan (Enterpreneurship), memberikan pelatihan kepada masyarakat untuk memanfaatkan fasilitas smartphone sebagai sarana layanan keuangan serta menghimbau masyarakat untuk melakukan studi banding pada desa yang telah maju perekonomian.

Tahap akhir dalam pelaksanan pengabdian kepada masyarakat ini berupa pelaporan hasil kegiatan program pengabdian kepada masyarakat pada mitra dengan cara memantau keberlanjutan pelaksanaan program pengabdian kepada masyarakat pada mitra, membuat hasil laporan pelaksanaan program pengabdian kepada masyarakat dan mempublikasikan laporan pelaksanaan program pengabdian kepada masyarakat agar bermanfaat sebagai informasi teknologi layanan keuangan dan kewirausahaan dalam rangka perbaikan ekonomi daerah, khususnya dan ekonomian Indonesia pada umumnya.

\section{Partisipasi Mitra.}

Selama pelaksanaan kegiatan pengabdian kepada masyarakat, Mitra berpartisipasi mulai tahap awal hingga tahap akhir dimana pada tahap awal perijinan, mitra berpartisipasi dalam memberikan informasi tentang permasalahan yang dihadapi mitra, memberikan perijinan kepada Fakultas Ekonomi dan Bisnis Universitas Pembangunan Nasional "Veteran" Jakarta untuk melakukan studi lapangan pada wilayah mitra dan memberikan perijinan program edukasi dan pembekalan Fintech dan kewirausahaan. Sedangkan pada tahap pelaksanaannya, mitra berpartisipasi dalam menyediakan konsumsi dan peralatan kerja. Dan pada tahap akhir melakukan pelaporan hasil pelaksanaan program pengabdian kepada masyarakat: Fakultas Ekonomi dan Bisnis Universitas Pembangunan Nasional 
"Veteran"Jakarta diberikan kewenangan untuk memantau keberlanjutan pelaksanaan program ini pada mitra.

\section{HASIL DAN PEMBAHASAAN}

Hasil dari pelaksanaan pengabdian kepada masyarakat di desa Iwul, Kecamatan Parung, Kabupaten Bogor, sebagai berikut :

\section{Diskripsi Data Profil UMKM Peserta Abdimas}

Tabel 2. Usia Peserta/Tahun

\begin{tabular}{ccc}
\hline Umur & Jumlah UMKM & Persentase \\
\hline $20-30$ & 2 & $6 \%$ \\
\hline $31-40$ & 18 & $53 \%$ \\
\hline $41-50$ & 13 & $38 \%$ \\
\hline$>50$ & 1 & $3 \%$ \\
\hline Jumlah & 34 & $100 \%$ \\
\hline
\end{tabular}

Tabel 3. Jenis Usaha

\begin{tabular}{lcc}
\hline Jenis Usaha & Jumlah UMKM & Persentase \\
\hline Warung Sembako & 4 & $12 \%$ \\
\hline Kue-kue & 7 & $21 \%$ \\
\hline Percetakan & 2 & $6 \%$ \\
\hline Fashion & 3 & $9 \%$ \\
\hline Salon \& kosmetik & 2 & $6 \%$ \\
\hline Ternak Ikan/Lele dan Ayam & 2 & $6 \%$ \\
\hline Tahu \& Tempe & 2 & $6 \%$ \\
\hline Jamu & 2 & $6 \%$ \\
\hline Pulsa & 1 & $3 \%$ \\
\hline Abon Lele & 1 & $3 \%$ \\
\hline Bengkel & 1 & $3 \%$ \\
\hline Jasa lainnya & 2 & $6 \%$ \\
\hline Tdk Ada Usaha & 5 & $15 \%$ \\
\hline & 34 & $100 \%$ \\
\hline
\end{tabular}

Tabel 4. Lama Usaha/ Tahun

\begin{tabular}{lcr}
\hline Tahun & Jumlah UMKM & Persentase \\
\hline$<1$ & 8 & $28 \%$ \\
\hline $2-3$ & 11 & $38 \%$ \\
\hline $4-5$ & 7 & $24 \%$ \\
\hline$>5-10$ & 3 & $10 \%$ \\
\hline & 29 & \\
\hline
\end{tabular}


Tabel 5. Jumlah Omset/ Bulan

\begin{tabular}{lcl}
\hline Jumlah Omset (Rp) & Jumlah UMKM & Persentse \\
\hline$\leq 1.000 .000$ & 3 & 10 \\
\hline $2.000 .000-4.000 .000$ & 9 & 31 \\
\hline $5.000 .000-7.000 .000$ & 8 & 28 \\
\hline $8.000 .000-10.000 .000$ & 3 & 10 \\
\hline$\geq 10.000 .000$ & 6 & 21 \\
\hline & 29 & 100 \\
\hline
\end{tabular}

Tabel 6. Jenis Fintech yang diunduh

\begin{tabular}{lcc}
\hline Jenis Fintech & Jumlah UMKM & Persentase \\
\hline Go Pay & 3 & $9 \%$ \\
\hline Go Food & 3 & $9 \%$ \\
\hline Ovo & 5 & $15 \%$ \\
\hline Kredivo & 2 & $6 \%$ \\
\hline Akulaku & 3 & $9 \%$ \\
\hline Belum Menggunakan & 18 & $53 \%$ \\
\hline & 34 & $100 \%$ \\
\hline
\end{tabular}

Berdasarkan data yang diperoleh selama pengabdian kepada masyakakat, diketahui profil pelaku UMKM desa Iwul yaitu dari 34 UMKM sebagai peserta, berusia antara $31-40$ tahun sebesar $53 \%$ dan usia 41 - 50 berada pada jumlah $38 \%$, dengan demikian $91 \%$ pelaku UMKM berada pada usia produktif. Bila dilihat dari jenis usaha pelaku UMKM sangat bervariasi dengan jumlah usaha terbanyak adalah berupa usaha kue sebesar $21 \%$ dan warung sembako sebesar $12 \%$. Lama usaha pelaku UMKM terbesar adalah pada usia usaha 2 - 3 tahun yaitu 38\% sedangkan pada usia usaha dibawah 1 tahun sebanyak $28 \%$ dan usia usaha $4-5$ tahun sebanyak $24 \%$ serta diatas $5-10$ tahun adalah $10 \%$. Dengan demikian sebagian besar pelaku UMKM adalah pelaku UMKM yang sudah mapan. Bila dilihat dari jumlah omset perbulan yaitu terbesar berada pada omset Rp.2.000.000 Rp.4.000.000,- sebanyak $31 \%$ dan pada omset Rp.5.000.000,- - Rp.7.000.000,- berada pada $28 \%$ serta pada omset diatas Rp.10.000.000,- sebesar 21\%. 57\% Pelaku UMKM telah menggunakan teknologi layanan keuangan (fintech) dengan mengunduh berbagai aplikasi unruk memenuhi kebutuhan layanan keuangannya seperti Gopay dan Gofood masingmasing sebesar 9\%, aplikasi Ovo sebesar $15 \%$, aplikasi Kredivo sebesar 6\% dan aplikasi Akulaku sebesar 9\%. Namun yang belum menggunakan aplikasi fintech masih cukup besar yaitu 53\% atau 18 orang pelaku UMKM. Hal ini dikarenakan sebagian belum memiliki smartphone yang mendukung untuk mengunduh aplikasi dan sebagian belum siap untuk menggunakan aplikasi layanan keuangan.

Dengan melihat pada profil pelaku UMKM di desa Iwul, maka pelaku UMKM desa Iwul mempunyai prospek yang cukup baik sehingga perlu didukung oleh keahlian menggunakan teknologi layanan keuangan dan keahlian kewirausahaan yaitu entrepreneurship dan interpersonal skill 


\section{Diskripsi Data Hasil Kuesioner Pengabdian Kepada Masyarakat}

Tabel 7. Pemahaman mengenai Fintech

\begin{tabular}{|c|c|c|c|c|c|c|c|c|}
\hline \multirow{2}{*}{$\begin{array}{c}\text { Butir } \\
\text { Pertanyaan }\end{array}$} & \multicolumn{2}{|c|}{1} & \multicolumn{2}{|c|}{2} & \multicolumn{2}{|c|}{3} & \multicolumn{2}{|c|}{4} \\
\hline & $\mathbf{F}$ & $\%$ & $\mathbf{F}$ & $\%$ & $\mathbf{F}$ & $\%$ & $\mathbf{F}$ & $\%$ \\
\hline 1 & 2 & 6 & 15 & 44 & 10 & 29 & 7 & 21 \\
\hline 2 & 3 & 9 & 10 & 29 & 15 & 44 & 6 & 18 \\
\hline 3 & 6 & 18 & 10 & 29 & 13 & 38 & 5 & 15 \\
\hline 4 & 6 & 18 & 16 & 47 & 6 & 18 & 6 & 18 \\
\hline 5 & 2 & 6 & 12 & 35 & 13 & 38 & 7 & 21 \\
\hline 6 & 3 & 9 & 11 & 32 & 13 & 38 & 7 & 21 \\
\hline 7 & 4 & 12 & 12 & 35 & 8 & 24 & 10 & 29 \\
\hline 8 & 1 & 3 & 14 & 41 & 13 & 38 & 6 & 18 \\
\hline 9 & 2 & 6 & 11 & 32 & 14 & 41 & 7 & 21 \\
\hline 10 & 2 & 6 & 10 & 29 & 14 & 41 & 8 & 24 \\
\hline 11 & 2 & 6 & 11 & 32 & 12 & 35 & 9 & 26 \\
\hline Total & & 97 & & 388 & & 385 & & 229 \\
\hline$\%$ Rata-rata & & 9 & & 35 & & 35 & & 21 \\
\hline
\end{tabular}

Sumber : Data diolah

Tabel 8. Pemahaman mengenai Kewirausaan : Enterpreneurship

\begin{tabular}{|c|c|c|c|c|c|c|c|c|}
\hline \multirow{2}{*}{$\begin{array}{c}\text { Butir } \\
\text { Pertanyaan }\end{array}$} & \multicolumn{2}{|c|}{1} & \multicolumn{2}{|c|}{2} & \multicolumn{2}{|c|}{3} & \multicolumn{2}{|c|}{4} \\
\hline & $\mathbf{F}$ & $\%$ & $\mathbf{F}$ & $\%$ & $\mathbf{F}$ & $\%$ & $\mathbf{F}$ & $\%$ \\
\hline 1 & 3 & 9 & 8 & 24 & 18 & 53 & 5 & 15 \\
\hline 2 & 2 & 6 & 9 & 26 & 16 & 47 & 7 & 21 \\
\hline 3 & 8 & 24 & 11 & 32 & 14 & 41 & 1 & 3 \\
\hline 4 & 2 & 6 & 9 & 26 & 14 & 41 & 9 & 26 \\
\hline 5 & 10 & 29 & 10 & 29 & 14 & 41 & 0 & 0 \\
\hline 6 & 3 & 9 & 15 & 44 & 8 & 24 & 8 & 24 \\
\hline 7 & 2 & 6 & 13 & 38 & 11 & 32 & 8 & 24 \\
\hline 8 & 1 & 3 & 11 & 32 & 12 & 35 & 10 & 29 \\
\hline 9 & 1 & 3 & 12 & 35 & 12 & 35 & 9 & 26 \\
\hline 10 & 1 & 3 & 7 & 21 & 15 & 44 & 11 & 32 \\
\hline 11 & 0 & 0 & 8 & 24 & 14 & 41 & 12 & 35 \\
\hline 12 & 8 & 24 & 8 & 24 & 16 & 47 & 2 & 6 \\
\hline 13 & 1 & 3 & 8 & 24 & 15 & 44 & 10 & 29 \\
\hline Total & & 124 & & 379 & & 526 & & 271 \\
\hline$\%$ Rata-rata & & 10 & & 29 & & 40 & & 21 \\
\hline
\end{tabular}

Sumber : Data diolah

Tabel 9. Pemahaman mengenai Kewirausahaan : Interpersonal Skill

\begin{tabular}{|c|c|c|c|c|c|c|c|c|}
\hline \multirow{2}{*}{$\begin{array}{c}\text { Butir } \\
\text { Pertanyaan }\end{array}$} & \multicolumn{2}{|c|}{1} & \multicolumn{2}{|c|}{2} & \multicolumn{2}{|c|}{3} & \multicolumn{2}{|c|}{4} \\
\hline & $\mathbf{F}$ & $\%$ & $\mathbf{F}$ & $\%$ & $\mathbf{F}$ & $\%$ & $\mathbf{F}$ & $\%$ \\
\hline
\end{tabular}




\begin{tabular}{|c|c|c|c|c|c|c|c|c|}
\hline 1 & 2 & 6 & 10 & 29 & 8 & 24 & 14 & 41 \\
\hline 2 & 2 & 6 & 8 & 24 & 9 & 26 & 15 & 44 \\
\hline 3 & 1 & 3 & 12 & 35 & 10 & 29 & 11 & 32 \\
\hline 4 & 0 & 0 & 13 & 38 & 9 & 26 & 12 & 35 \\
\hline 5 & 0 & 0 & 13 & 38 & 11 & 32 & 10 & 29 \\
\hline 6 & 2 & 6 & 10 & 29 & 13 & 38 & 9 & 26 \\
\hline 7 & 3 & 9 & 11 & 32 & 10 & 29 & 10 & 29 \\
\hline 8 & 2 & 6 & 16 & 47 & 6 & 18 & 10 & 29 \\
\hline 9 & 3 & 9 & 14 & 41 & 8 & 24 & 9 & 26 \\
\hline Total & & 44 & & 315 & & 247 & & 294 \\
\hline$\%$ Rata-rata & & 5 & & 35 & & 27 & & 33 \\
\hline
\end{tabular}

Sumber : Pengolahan Data

Pemahaman mengenai fintech $56 \%$, yaitu $35 \%$ menjawab dengan kriteria memahami dan 21 $\%$ menjawab dengan kriteria sangat memahami, dengan demikian pencapaian hasil pengabdian kepda masyarakat mengenai pemahaman akan fintech belum memenuhi harapan yaitu belum mencapai $70 \%$. Dengan demikian masih diperlukan waktu lagi untuk memberikan edukasi fintech agar pemahaman para pelaku UMKM lebih meningkat.

Sedangkan pemahaman mengenai Kewirausaan : Enterpreneurship sebesar $61 \%$, yaitu $40 \%$ dengan kriteria memahami dan $21 \%$ dengan kriteria sangat memahami. Pemahaman mengenai Kewirausahaan : Interpersonal Skill sebesar 60\% dengan kriteria memahami $27 \%$ dan sangat memahami $33 \%$. Pencapaian hasil pengabdian kepada masyarakat mengenai Enterpreneurship belum tercapai seperti yang diharapkan yaitu dengan pencapaian $70 \%$. Untuk itu masih diperlukan pendalaman lagi mengenai materi kewirausahaan agar pelaku UMKM dapat lebih memiliki keterampilan kewirausahaan yang dapat menunjang peningkatan usaha UMKM.

\section{KESIMPULAN DAN SARAN}

\section{Kesimpulan}

Berdasarkan hasil pembahasan dapat disimpulkan bahwa pelaku UMKM di desa Iwul Kecamatan Parung, Kabupaten Bogor memiliki potensi untuk menjadi UMKM naik kelas dimana rata-rata berada pada usia produktif dengan omset penjualan perbulan yang relatif tinggi dan lama usia melakukan kegiatan usaha cukup mapan serta produk yang dihasilkan bervariasi. Namun berdasarkan hasil kuesioner yang diberikan pemahaman pelaku UMKM terhadap fintech masih belum mendalam begitu juga dengan pemahaman mengenai kewirausahaan. Hal ini dapat disebabkan dimana keadaan wilayah desa Iwul yang jauh dari perkotaan dan keramaian. Dan pelaku UMKM masih menjalankan usahanya lebih mengarah secara tradisional, belum banyak menggunakan teknologi.

\section{Saran}

Dengan melihat pada permasalahan yang ada dan data hasil pengabdian kepada masyarakat yang telah diolah, dimana masih menunjukkan hasil yang belum memuaskan karena belum tercapainya persentase indikator ketercapaian, maka hal yang dapat disarankan adalah perlunya dilakukan pengabdian kepada masyarakat lebih intensif lagi dan diperlukan pula 
kolaborasi dari berbagai pihak terkait yaitu pemda setempat melalui dinas UMKM, pengusaha yang telah berhasil turut memberikan dukungan untuk meningkatkan UMKM.

\section{Ucapan Terima Kasih (Acknowledgement)}

Dalam kesempatan ini kami, tim pengabdian kepada masyarakat Fakultas Ekonomi UPN Veteran Jakarta, mengucapkan terimakasih yang tak terhinga kepada pihak-pihak yang turut mendukung terlaksananya pengabdian kepada masyarakat di desa Iwul, Kecamatan Parung, Kabupaten Bogor ini yaitu kepada Bapak Camat Parung, Forum UMKM kecamatan Parung, para pelaku UMKM desa Iwul serta ucapan terimakasih juga kepada Rektor dan Ketua LPPM UPN Veteran Jakarta.

\section{REFERENSI}

Abyan, M.A. (2018). Konsep Penggunaan Financial Technology dalam Membantu Masyarakat Sub Urban di Indonesia dalam Melakukan Transaksi Finansial https://www.researchgate.net/publication/324386435

Andersson, T., \& Formica, P., \& Curley, M.G.(2009) "Knowledge-Driven Entrepreneurship: The Key to Social and Economic Transformation" Publisher: Springer

Bank Indonesia. (2017). Edukasi Perlindungan Konsumen.

https://www.bi.go.id/id/edukasi-perlindungan-konsumen/edukasi/produk-dan-jasasp/fintech/Pages/default.aspx

Bohang, F.K . (2018).Berapa Jumlah Pengguna Internet Indonesia, https://tekno.kompas.com/read/2018/02/22/16453177/berapa-jumlah-penggunainternet-indonesia.

Chrismastianto, I.A.W. (2017). Analisis Swot Implementasi Teknologi Finansial Terhadap Kualitas Layanan Perbankan Di Indonesia, 20 ( 1)

Davis, K., Maddock, R., \& Foo, M. (2017). Catching up with Indonesia's fintech industry. Law and Financial Markets Review, 11(1), 33-40. DOI: 10.1080/ 17521440.2017.1336398,https://research.monash.edu/en/publications/catching-upwith-indonesias-fintech industry

Fintech dan Transformasi Industri Keuangan.(2017), https://www.pwc.com/id/en/mediacentre/pwc-in-news/2017/indonesian/fintech-dan-transformasi-industri-keuangan.html

https://www.duniafintech.com/perbedaan-p2p-lending-crowdfunding/

https://konsumen.ojk.go.id/minisitedplk/images/upload/201807131451262/Fintech.pdf

http://wartaekonomi.co.id/berita16992/indonesia-masih-berupaya-tingkatkan-jumlah wirausaha.html

Kurniawan, I. (2018) https://id.techinasia.com/startup-fintech-lending-indonesia-2018

Mujib, M.K(2010), Analisis Faktor-Faktor Yang Berpengaruh Secara Langsung dan Tidak Langsung Terhadap Kinerja Usaha Kecil \& Menengah (UKM), Studi Pada Pelaku UKM Di Kabupaten Kebumen, FE UNDIP, Semarang

Muzdalifa, I., Rahma, I.A., Novali. B.G. (2018). Peran Fintech Dalam Meningkatkan Keuangan Inklusif Pada UMKM Di Indonesia (Pendekatan Keuangan Syariah),Jurnal Masharif al-Syariah: Jurnal Ekonomi dan Perbankan Syariah/Vol.3, No.1 
Nielsen, C. \& Morten,L. (2014). Business Model Design: Innovating and Globalizing $-2^{\text {nd }}$ edition, ISBN 978-87-403-0639-2

OJK.(2017). Kajian Perlindungan Konsumen Sektor Jasa Keuangan: Perlindungan Konsumen Pada Fintech Jakarta. Departemen Perlindungan Konsumen OJK, 2017.

Panggabean, E.V. (2017). Empat Fungsi Bank Indonesia, https://ekbis.sindonews.com /read/1155326/178/ini-empat-fungsi-bank-indonesia-fintech-office

Peraturan Otoritas Jasa Keuangan Nomor 77 /POJK.01/2016, Tentang Layanan Pinjam Meminjam Uang Berbasis Teknologi Informasi

Rachma \& Kadian,R. (2013), Key Success Factors Of Micro, Small And Medium Entrepreneurs : An Empirical Investigation, International Journal of Management (IJM), ISSN 0976 - 6502 (Print), ISSN 0976 - 6510 (Online), Volume 4, Issue 6, November - December (2013), India

Wetherington, L.(2014) The Innovation Question Navigating the Future of FinTech and Payments, Jack Henry \& Associates, Inc

Scarborough, N.M. \& Scott, W.H(2012), Effective Small Business Management An Entrepreneurial Approach, Tenth Edition, New Jersey: Pearson Education,

Sebastian Atmodjo, https:/finance.detik.com/moneter/d-4192994/ojk-terbitkan-aturan-barusoal-fintech-ini-isinya

Simon Iqbal Fahlevi, Peran Teknologi Finansial Serta Regulasinya di Indonesia https://www.jurnal.id/en/blog/peran-teknologi-finansial-serta-regulasinya-diindonesia

Suryana (2013) Kewirausahaan : Kewirausahaan (Kiat dan Proses Menuju Sukses) e4, Penerbit Salemba Empat, Jakarta

Warta Ekonomi.co.id, Jakarta - Ini Prospek Ekonomi Indonesia 2018 Versi BI

Yogie Maharesi, http://feb.ub.ac.id/fintech-dan-ancaman-baru-dalam-sistem-perbankan. 